\title{
Exploring Factors that Influence Academics' Knowledge Sharing Behaviour in Higher Education Institutions
}

\author{
Ashwaq Rushud Al Rushud ${ }^{1}$ \\ ${ }^{1}$ King Saud University, Riyadh, Saudi Arabia \\ Correspondence: Ashwaq Rushud Al Rushud, King Saud University, Riyadh, Saudi Arabia.
}

Received: March 8, 2021

Accepted: April 13, 2021

Online Published: April 19, 2021

doi:10.5539/ibr.v14n5p40

URL: https://doi.org/10.5539/ibr.v14n5p40

\begin{abstract}
This study explores the organisational and individual factors that influence knowledge sharing behaviour among UK universities' academics. Furthermore, the research also aims to provide recommendations on how knowledge sharing can be promoted. Few studies have been conducted to explore Knowledge Sharing behaviour in the context of higher education institutions. This research sheds light on the factors that influence knowledge sharing behaviour in higher learning institutions.

Data for this research were collected from sixteen academics from four UK universities using semi-structured interviews and snowball sampling technique. The interview data was thematically analysed using Nvivo12 software. The interviews reveal that there is a positive attitude among academics toward knowledge sharing. Furthermore, there are several factors (organisational and individual) affecting knowledge sharing behaviour, such as unsupportive leadership, lack of facilities and lack of an effective rewards system.
\end{abstract}

Keywords: knowledge sharing, knowledge management, university academics, UK universities

\section{Introduction}

The current business system is a knowledge-based system where knowledge has emerged as the most critical asset of any organisation. It is not only essential for differentiation and competitive advantage but has become an essential ingredient in the sustainability needs of organisations. This is even more critical for organisations like universities that are focused on knowledge exchange. Knowledge sharing (KS) is critical for universities because universities are in the business of knowledge creation and sharing (Al-Kurdi, El-Haddadeh, \& Eldabi, 2020). It is essential for collaborative research work and significantly boosts the organisational research environment (Tan, 2016). Researchers and academics accumulated knowledge through years of work and experience. KS makes it easier for this knowledge to be transferred to other individuals, which benefits the whole group of academics and ensures that vital knowledge is not lost. Not all individuals document their knowledge, and not all knowledge can be documented. In this respect, knowledge sharing allows for knowledge conservation and knowledge building. KS allows knowledge transfer in the most efficient manner because it ensures not only the transfer of knowledge but also the adequate synthesis of the information contained within. Individuals may learn efficiently through their interaction with others. Certain factors catalyse the process of knowledge sharing. Tan (2016) categorised these factors as (1) individual, (2) organisational, (3) technological, and (4) communication factors.

$\mathrm{KS}$ is critical for intellectual and academic development of the students and building an environment that facilitates KS can improve the overall development of the students. It is therefore, imperative for universities to build an environment that facilitates and promotes knowledge sharing (Al-Kurdi et al., 2020). Many authors have talked about the significance of KS in academic institutions, but there remains work to be done on identifying the factors that facilitate KS in academic organisations (Al-Kurdi, El-Haddadeh, \& Eldabi, 2018). This research is aimed at identifying the factors that influence academics' knowledge sharing behaviour in higher education institutions. Identifying these factors may be useful in building an overall institutional environment that facilitates KS and leads to a productive and constructive work environment.

\section{Literature Review}

\subsection{Understanding Knowledge Sharing}

Knowledge is identified as an important resource and an invisible factor associated with improving organisational outcomes. Knowledge sharing is an important activity through which people share or exchange 
their knowledge with friends, family, peers, colleagues or communities. Knowledge sharing is an important approach to enhancing or promoting professional skills and competencies (Yu \& Zhou, 2015). Bibi and Ali (2017) have defined knowledge sharing as the "behaviour of the knowledge provider to make knowledge available to the others in the organisation" (p. 551). However, an important factor in knowledge sharing is the quality of shared knowledge (Chirawattanakij \& Ractham, 2016). Knowledge sharing is as important as knowledge generation as the bulk of knowledge reside in an employee and is of no importance until those are shared and applied (Al-Husseini \& Elbeltagi, 2015). Lee et al. (2010) and Chuang et al. (2016) supported the significance of knowledge sharing by identifying a positive relationship between knowledge sharing within teams and team-level innovation performance.

With the development or enhancement of the knowledge sharing, skills, competencies and attitude of the employees are influenced (Al-Kurdi et al., 2018). Knowledge sharing is considered to be crucial for the success of knowledge management initiatives. This process is also associated with a mutual exchange of knowledge, but knowledge hoarding could be a factor that could limit mutual sharing (Al-Kurdi et al., 2020). Knowledge sharing is also differentiated into two important forms. The first is explicit knowledge sharing, which is relatively easier as explicitly, knowledge can be shared through written information or manuals (Fullwood \& Rowley, 2017). However, another form of knowledge sharing is tacit knowledge, which is an implicit form of knowledge, which could be difficult to share through verbal or written information, as it is unarticulated and intuitive (Tan, 2016). Informal methods may be needed to share this tacit knowledge but success of such informal methods may depend on the comfort level and trust between the individuals. According to Boyd et al., (2007) knowledge sharing is a two-way, mutual and voluntary process that generally occurs during social and informal interactions among an organisation's employees. The process involves one or several owners and one or more recipients, and each party involved in the process can be a knowledge owner and a recipient simultaneously.

\subsection{Significance of Knowledge Sharing Behaviour among University Academics}

Marouf (2016) informs that the purpose of knowledge sharing is to enhance organisational resources and organisational efficacy. Therefore, organisation culture has a significant impact on knowledge sharing. Yu and Zhou (2015) argued that university teachers or academics display specialisations and contribute towards cultivating talents. This is the reason that they are characterised by innovation, skills, high-quality knowledge. Yu and Zhou (2015) further argued that academics at universities or in higher education are required to refine their knowledge in their field, for which they regularly need to update their knowledge and competencies. Therefore, knowledge sharing is identified as an important approach towards expanding and extending their knowledge system in order to break through the bottleneck of developing professional quality.

Knowledge sharing is identified as an important approach towards enhancing organisational capabilities and improving the competencies of employees (Yang et al., 2017). Al-Kurdi et al. (2020) espoused that universities are a knowledge-intensive organisation that plays an important role in creating and disseminating knowledge to the students, as well as to the wider society. Therefore, knowledge management and knowledge sharing within universities are important for harnessing competitive advantage. Academics are considered as the knowledge leaders who should not be reluctant towards sharing knowledge and should focus more on achieving the goals of universities rather than individual attainment (Al-Kurdi et al., 2018).

Annansingh et al. (2018) argues that the process of knowledge sharing in higher education is mutually beneficial for the institutions as well as for the academics, as knowledge sharing promotes higher-level skills for problem-solving, enhancing professional skills, and adds value to the institution by contributing towards new ideas.

\subsection{Factors Affecting Knowledge Sharing Behaviour}

A study conducted by Akosile and Olatokun (2020) espoused that gender may have an influence or effect on knowledge sharing, while the faculty and academic level may not. The study further informs that personal belief, personal satisfaction, mentoring, personal level of knowledge and sponsorship/funds are the other factors that affect the knowledge sharing behaviour. Shahzadi, Hameed, and Kashif (2015) conducted a questionnaire survey with the university Academics of Pakistan to understand the effect of individual factors on knowledge sharing. A study conducted by Fullwood and Rowley (2017) investigated the factors affecting knowledge sharing among UK academics and informs that individual factors were more significant in terms of affecting knowledge sharing behaviour among UK academics than organisational factors.

Knowledge sharing culture is a vital component in the success of organisations, especially in higher education institutions. According to Daud and Abdul Hamid (2018), educational institutions are expected to have formal and well-structured approaches on how to manage and expand their knowledge capacities. However, Daud and 
Abdul Hamid (2018: 123) found that it is, in fact, the opposite as universities were observed to be both "passive and inconsistent" in developing their knowledge management and sharing strategies. Knowledge sharing can be more successful with the proactive approach of the leaders and the acceptance of the rest of the stakeholders. As per Sadiq Sohail and Daud (2009: 138), the "nature of knowledge, working culture, attitude, motivation to share, and opportunities" are all important factors that influence knowledge sharing in universities. Further, Daud and Abdul Hamid noted the need for management support, the presence of resources and infrastructure, and technology. Seonghee and Boryung (2008) discussed how attitudes towards knowledge sharing and collaboration between all stakeholders must also be present in the process of reaching optimum benefits and advantages of knowledge sharing in educational institutions.

Shahzadi et al. (2015) reported that organisational culture, structure and rigid organisational regimes could pose a barrier for knowledge sharing among university academics because they believe that organisational culture is significantly formed on the basis of national culture, values and norms. The bureaucratic cultural norms and individual's perception about losing advantage and status can be the barrier that may affect knowledge sharing. Fullwood, Rowley, and McLean (2019) have argued that organisational culture within universities is different from that in business corporates, where the knowledge sharing culture is aligned with organisational goals. Therefore, it is argued that corporate culture does not exist in universities, and universities are required to invest in identifying their own sub-culture (Fullwood et al., 2019).

Most universities or educational institutions depict hierarchical, competitive and individualist culture, where the focus of academics is more on personal advancement rather than organisational goals (Fullwood \& Rowley, 2017). Ramjeawon and Rowley (2017) identified organisational leadership as a barrier as well as an enabler in affecting knowledge sharing in higher education institutions. Ramjeawon and Rowley (2017) have informed that organisational leadership can play a significant role in cultivating and encouraging knowledge sharing among academics, as they are in a position to manage the processes through which staff transfer and share knowledge. An academic leader is considered to be an individual who is respected and professionally recognised for their skills and capabilities. Such leaders can hold power and authority to adopting and guiding academics towards knowledge sharing behaviour.

According to economic exchange theory, it is determined that an individual would behave or perform in a certain manner that would be coherent with their self-interest (Al Kurdi, 2017). According to which reward system could be significantly associated with the motivation of university academics towards knowledge sharing (Tan, 2016). The economic exchange also informs about the rational way of calculating benefits that one shall receive through sharing knowledge, and once the rewards exceed the cost, individuals will be positively involved in knowledge sharing behaviour. According to Phung et al. (2019), economic and social exchange theories further informs that individuals will participate in exchange behaviour when they are sure that reward will justify the cost. Motivation to share personal explicit, as well as implicit knowledge, is positively associated with knowledge sharing behaviour among employees. Tan (2016) has further argued that when an organisation of higher education institution lacks a transparent reward system or monetary terms for encouraging knowledge sharing, then they are likely to suffer from poor knowledge sharing among staff members.

Bibi and Ali (2017) have argued that academics may be influenced by intrinsic and extrinsic motivating factors. For example, expecting personal benefit can motivate them to share knowledge, while the fear of losing personal and valuable resources may pose a barrier in knowledge sharing. Studies have also identified that intrinsic motivation can be associated with the willingness and pleasure that one receives on sharing knowledge (Dee \& Leisyte, 2017). Therefore, intrinsic motivations, such as receiving rewards as promised, getting recognition, and a sense of pleasure in helping others, are intrinsic motivation factors that positively influence knowledge sharing behaviour. Annansingh et al. (2018) argued that personal decision-making in knowledge sharing is also found to be an important factor among university teachers, which is associated with weighing risks and values of knowledge sharing, and only when they weigh that values are higher than perceived risks, they will contribute towards tacit knowledge sharing.

Bibi and Ali (2017) informed that Technological factors offered by the organisations are also considered to be significant in affecting knowledge sharing among university academics. It is also identified that universities that invest in the development of technology and communication tools, such as the internet, intranet, chat rooms, emails and bulletin boards, are likely to support positive knowledge sharing among academics. However, Jiang and $\mathrm{Hu}(2016)$ have argued that availability of the modern technological and communication tools does not guarantee that employees will use them for knowledge sharing purpose; rather, they would be inclined towards knowledge sharing according to their personal belief about using technology, and ease of using such tools. 
A study by Wang and Hou (2015) argued that interpersonal trust is also an important factor that affects knowledge sharing behaviour. Wang and Hou (2015) also identified that trust was more important than technical support because it removes the chances of cheating, deception and tendency of blaming others. When there is a lack of trust among academics, they would be reluctant to share knowledge with others because of the fear of losing their own reputation and position. Therefore, weak inter-organisational bonds can be the negative factor affecting knowledge sharing behaviour among academics (Raza \& Awang, 2020).

Some of the other important factors that could be associated with affecting knowledge sharing behaviour of the academics are job satisfaction (associated with loyalty towards organisation and willingness to share knowledge) (Bibi \& Ali, 2017), job involvement (associated with feeling confident, involved and sufficiently supported) (Fullwood \& Rowley, 2017), and psychological elements (associated with the personal position, reputation and sense of self-worth) (Annansingh et al., 2018). Therefore, a wide array of factors affects the knowledge sharing behaviour among university academics. Studying these factors may help in creating an environment favourable for knowledge sharing.

\section{Methodology}

This study explored university academics' perception of the factors that they believe affected their knowledge sharing behaviour. Since this was an exploratory study, a subjectivist ontology and interpretivist epistemology guided the methodological approach.

Face to face semi-structured interviews were conducted with 16 academics working in four different UK universities. Academics who have taught in UK universities for over ten years were recruited using the snowball technique. This ensured that the participants had sufficient experience of working in a university environment and can, therefore, provide meaningful data. After obtaining approval from their employing organisation, participants were asked to provide their informed consent. They were informed of their rights of withdrawal without consequences and voluntary participation. All respondents were guaranteed anonymity, and hence respondents were identified by proxy codes rather than their names, as indicated in Table 1.

Respondents were asked to reflect on their professional lives in an academic environment and were asked to mention, in general, what factors may facilitate or hinder knowledge sharing among university academics. Respondents were not necessarily referring to their own employing organisation when responding to the questions, and consequently, there was little possibility of a feeling of embarrassment or shame for their employing organisation.

Qualitative interview data was thematically analysed using manual coding technique. Thematic analysis is useful for exploratory studies as data inform the researcher of the emergent themes. Data analysis began in a funnelling pattern starting with broad themes and gradually narrowing down to sub-themes.

\section{Data Analysis}

\subsection{Sample Analysis}

Table 1. Profiles of interviewees

\begin{tabular}{|l|l|l|l|}
\hline Code & Position & $\begin{array}{l}\text { Total-experience } \\
\text { (years) }\end{array}$ & Department \\
\hline R1 & Professor & 14 & Politics and International Relations \\
\hline R2 & Senior Professor & 23 & Economics \\
\hline R3 & Head of Department & 26 & Sociology \\
\hline R4 & Professor & 15 & Finance \\
\hline R5 & Professor & 13 & Economics \\
\hline R6 & Senior Professor & 20 & History \\
\hline R7 & Lecturer & 16 & Economics \\
\hline R8 & Head of Department & 25 & Politics and International Relations \\
\hline R9 & Professor & 19 & Sociology \\
\hline R10 & Head of Department & 31 & Sociology \\
\hline R11 & Head of Department & 32 & History \\
\hline R12 & Professor & 11 & International politics \\
\hline R13 & Professor & 22 & Risk Management \\
\hline R14 & Professor & 16 & Risk Management \\
\hline R15 & Professor & 20 & Business Management \\
\hline R16 & Professor & 18 & International business \\
\hline
\end{tabular}

Table 1 gives the profile of the respondents. Only academics with more than ten years of experience were recruited for this research. Respondents were from different departments and belonged to four different UK universities. 


\subsection{Data Analysis}

\subsubsection{Significance of Knowledge Sharing}

All of the respondents agreed that knowledge sharing is critical for universities

R1: "It is impossible for universities to survive without adequate knowledge sharing because as academics, we know that we only grow as a community. It's not possible for us to grow in isolation."

R4: "This is the heart and soul of our profession. We exchange knowledge not only with our peers but also with our students; we learn from every individual we meet because everyone has an abundance of their own knowledge to share."

R6: "There is so much information out there, and new information is being continuously uncovered. As human beings, we have limited time and resources to learn all this, especially if we try to do this on our own. Knowledge sharing is the only way for us to get most of this knowledge." The same point was expanded upon by R11: "as individuals, we can easily access information. There is so much out there on the internet and media. But information is different from knowledge. To get maximum knowledge, you have to rely on experts and the only way to get it is through knowledge exchange." R15 also stressed that "with our hectic schedules and with abundance of information, knowledge sharing has become key to our development."

Respondents emphasised the point that universities are institutions of knowledge exchange, and hence it is absolutely essential for them to create an environment that facilitates knowledge exchange rather than hindering it. R10: "UK universities have a great reputation for research, and it is all because we have a good knowledge exchange environment." Nine other respondents mentioned that knowledge exchange is critical for research work and hence an absolute essential for universities. R3: "There is so much cross-discipline work right now that it is imperative for us to have knowledge sharing. Now you will see the finance domain merging with the IT domain or the IT domain merging with the social science domain. In such an environment, cross-field knowledge sharing is an absolute necessity." R16 commented: "I am sure I have learnt more from my colleagues in last one year alone than I have learnt in five years of self study. There is no comparison between the two."

\subsubsection{Factors Facilitating Knowledge Exchange}

Respondents cited a number of factors that facilitate knowledge exchange in universities. The most common of these factors was the overall culture. R3: "knowledge exchange is often dependent on culture. Universities are often characterised by how open they are for diverse debates and discussions." R5: "having a culture of knowledge exchange is essential. This is the reason why some universities have more knowledge exchange among academics than others. Because they have an institutional culture of knowledge sharing." Most individuals spoke about culture and suggested that knowledge sharing often depends on the organisational culture. R9: "good universities have this culture of knowledge sharing, and that is why academics in such universities are so exemplary." R14 agreed: "good universities encourage knowledge exchange through direct knowledge exchange programs like seminars and all. It is mandatory for my PhD students to attend because I know how useful these are for knowledge exchange."

In terms of knowledge sharing culture, most respondents pointed towards leadership as well. R7: "it depends a lot on leadership. Management needs to promote a culture of knowledge sharing among peers. Such as organising open discussion sessions on diverse subjects." R3: "management should try to build a system which not only gives opportunities to share knowledge but also incentivise people to do so." R7: "it is up to the management to develop a culture of knowledge sharing by adopting the right policies for this." This is overall beneficial for the universities because it improves the overall academic environment of the universities.

Eight respondents mentioned the functional structure as a key factor. R10: "decentralised structures lead to healthier relationships amongst faculty members, and this eventually promotes knowledge sharing." R13 commented: "Individuals need to take initiatives regarding knowledge exchange It cannot be forced. So, I think individuals should be allowed and to some extent motivated to pursue initiatives regarding knowledge sharing." R12 commented "people should be allowed to make their decisions regarding knowledge sharing". Respondents suggested that in a centralised organisational structure, there is high power distance amongst different team members, which may affect their willingness and even ability to share their knowledge. In decentralised, low power distance structures, team members may be more open to engaging in conversation with their colleagues, and this may facilitate better knowledge sharing.

Respondents also mentioned opportunities to exchange knowledge. According to R6: "organisations need to give individuals opportunities to exchange knowledge." In this respect, the respondents mentioned that universities need to organise events where individuals can interact and exchange knowledge. Such formal and informal 
sessions can be quite useful not only for individuals to get to know each other's area of expertise but also to develop a comfort level which is essential for knowledge sharing. R10: "quite often individuals do not know who to ask for information even though there are many individuals in their circle who can help." Five other respondents mentioned the need for informal/casual meetings between staff members for building ground for trust and comfort, which eventually may lead to knowledge sharing. R11 mentioned that this is the role of the leadership to integrate such meetings within the overall system.

Respondents also mentioned the need for a system that actively promotes knowledge sharing by motivating/ rewarding the individuals who engage in such exercises. R7: "it is often some effort from individuals to share their knowledge, and unless there is some reward, even if it is non-materialistic such as recognising their efforts publicly, it creates a sort of barrier for individuals to waste their efforts for nothing." In this respect, individuals suggested developing a system where individuals are credited for their efforts towards knowledge sharing. Respondents suggested that developing a sense of belonging is essential. R8: "Academics are more likely to share their knowledge if they feel a sense of association or belonging with the institution." According to the respondents, if the academics believe that it is their moral responsibility to contribute to the overall improvement of the institution, then they are likely to consider it their responsibility to share their knowledge. This sense of belonging often is linked with the psychosocial bonding that the academics may have with the institution and its members.

Three respondents mentioned developing a proper IT system that facilitates knowledge sharing among peers, not only within the institution but also beyond it. R2: "knowledge sharing should not be limited to the University. Today we have the technology to share knowledge with people worldwide." R11: "Universities need to update their system to make it easier for individuals to interact, say through video calls." Sharing knowledge takes time, and effort and technological tools can be used to minimise time and effort to share knowledge. For example, individuals can post video logs for people to watch as and when they need them. In this respect, technology can make knowledge sharing easier in real-time as well as acting as a knowledge bank for future access. But for this, the systems need to be more advanced than mere web-based servers, as in that case, they will be merely replicating the popular world wide web model.

Eight respondents also mentioned the physical environment in the universities. R2: "in certain environments, people tend to engage more in conversation, such as when they are comfortable and feeling pleasant." R4: "open and pleasant environment leads to more constructive and positive knowledge sharing. When people are confined to their small rooms, they are very less likely to engage in knowledge sharing." R11: "People tend to spend more time at the workplace if they feel good. They will try to hide or run away from the workplace if they don't like it. And unless they stay, how will they share knowledge." Most respondents suggested that universities with open, sociable spaces make for better and more productive knowledge sharing as individuals could relax, sit and engage in relaxed conversations. On the other hand, closed congested spaces deter individuals from engaging in conversation and share their knowledge with others.

\subsubsection{Barriers to Knowledge Sharing}

Excessive performance pressure was cited by most respondents as one key barrier in knowledge sharing among academics. R7: "performance pressure negatively affects knowledge sharing because it puts too much emphasis on individuality over collectivity." According to the respondents, overemphasis on individual goals and targets tend to suppress collectivity and team working, which also affect knowledge sharing attitude within organisations. In academic organisations, knowledge leads to competitive advantage, and if the individuals are forced to compete, they will try to protect their competitive advantage.

Another key barrier mentioned was poor workload management which limits the free time that academics have to interact with each other for knowledge sharing. R1: "Academics are so overburdened with organisational and their own work that they hardly get time to interact and share their knowledge." Four other respondents mentioned the shortage of time and excessive work pressure, which may deter individuals from taking time out to share their knowledge. In this respect, R10 recommended that organisations should try and make knowledge sharing part of an individual's job profile. This is part of building a culture of knowledge sharing. However, this is possible only if the top leadership acknowledges the benefits of knowledge sharing.

\section{Discussion}

The study aimed to explore different factors that affect sharing knowledge among academics in UK universities. All interviewees suggested that knowledge sharing is very important for universities and academics. With the amount of information available, it is not possible for any individual to collect and process so much information on their own. Knowledge sharing minimises the efforts in knowledge acquisition provided all the members of the 
team do so selflessly.

Cross stream knowledge sharing is useful as individuals can find connections and relations between different streams. Such connections are rapidly evolving as many streams are converging, and knowledge sharing helps academics in overcoming any gaps in knowledge that they might have.

In terms of the factors that facilitate KS, the first and foremost factor mentioned by the respondents was organisational culture. Organisations which actively promote knowledge sharing through targeted policies and systems are likely to see more knowledge sharing activity. For example, such organisations may organise more formal and informal events for academics to share their knowledge and views with others.

Leadership plays quite a vital role in improving the culture and environment for knowledge sharing through the right policies. For example, institutional policies could involve setting job profiles that contain elements of knowledge sharing and, furthermore, rewarding individuals for knowledge sharing. Respondents suggested that having flatter organisations reduce the power distance between team members, and this enhances knowledge exchange. Sometimes the high-power distance between organisational team members can inhibit their willingness to share knowledge.

The more opportunities and facilities organisations provide for knowledge sharing better is the overall knowledge environment of the organisation. In this respect, the management should seek to eliminate any physical, social or psychological barriers that may prevent people from sharing their knowledge. Informal meetings between academics can help build trust and ground for the exchange of knowledge. Such social cohesion, where team members feel moral responsibility for the overall development of the organisation, can be a useful catalyst for knowledge sharing. Respondents suggested that the physical workplace environment is a useful aspect in this respect. Open and pleasant areas within the workplace can lead to more openness and willingness amongst individuals to engage in constructive discussions and share their knowledge. The technology was also mentioned as a tool that can be deployed effectively for individuals to share their knowledge with the team members.

On the other hand, excessive performance pressure may increase competitiveness amongst academics, and this may inhibit their willingness to share their knowledge as this may erode their competitive advantage. Additionally, poor workload management, which restricts the free time available for academics, may also inhibit their ability and willingness to share their knowledge.

\section{Conclusion}

This study has been conducted with the objective to explore which are individual and organisational factors that can hinder and foster knowledge sharing practices among the individuals and within the departments of a university. Furthermore, the study also uncovered which factors can improve the knowledge sharing practices among individuals and within the departments of a university. The results of this study concluded that organisational culture, systems and policies, as well as leadership and its approach towards knowledge sharing, has a significant influence on academics' knowledge sharing behaviour. In addition, the physical space design of the University as well as opportunities to engage and interact affect academics ability and willingness to share knowledge with each other. On the other hand, excessive performance pressure and poorly managed workload could inhibit academics ability to share knowledge. People own their knowledge and they decide who will they share it with, when and how. So, unless these knowledge owners are allowed to control these variables, they will not commit themselves to knowledge sharing. Hence, decentralised structures are likely to facilitate knowledge sharing.

\section{References}

Akosile, A., \& Olatokun, W. (2020). Factors influencing knowledge sharing among academics in Bowen University, Nigeria. Journal of Librarianship and Information Science, 52(2), 410-427. https://doi.org/10.1177/0961000618820926

$\mathrm{Al}$ Kurdi, O. F. (2017). Knowledge-sharing management in the context of higher education institutions. Doctoral dissertation, Brunel University London.

Al-Husseini, S., \& Elbeltagi, I. (2015). Knowledge sharing practices as a basis of product innovation: A case of higher education in Iraq. International Journal of Social Science and Humanity, 5(2), 182. https://doi.org/10.7763/IJSSH.2015.V5.449

Al-Kurdi, O., El-Haddadeh, R., \& Eldabi, T. (2018). Knowledge sharing in higher education institutions: a systematic review. Journal of Enterprise Information Management, 31(2), 226-246. 
https://doi.org/10.1108/JEIM-09-2017-0129

Al-Kurdi, O. F., El-Haddadeh, R., \& Eldabi, T. (2020). The role of organisational climate in managing knowledge sharing among academics in higher education. International Journal of Information Management, 50, 217-227. https://doi.org/10.1016/j.ijinfomgt.2019.05.018

Annansingh, F., Howell, K. E., Liu, S., \& Nunes, M. B. (2018). Academics' perception of knowledge sharing in higher education. International Journal of Educational Management, 32(1). https://doi.org/10.1108/IJEM-07-2016-0153

Bibi, S., \& Ali, A. (2017). Knowledge sharing behaviour of academics in higher education. Journal of Applied Research in Higher Education, 9(4), 550-564. https://doi.org/10.1108/JARHE-11-2016-0077

Boyd, D. J., Hamilton, L., Susanna., J. E. R., \& James, H. W. (2007). The Narrowing Gap in New York City Teacher Qualifications and Its Implications for Student Achievement in High-Poverty Schools. CALDER Working Paper 10. Washington, DC: The Urban Institute. https://doi.org/10.3386/w14021

Chirawattanakij, S., \& Ractham, V. V. (2016). Enhancing knowledge adoption with recipients' characteristics. Journal of Management Development, 35(1), 38-57(20). https://doi.org/10.1108/JMD-11-2014-0155

Chuang, C. H., Jackson, S. E., \& Jiang, Y. (2016). Can knowledge-intensive teamwork be managed? Examining the roles of HRM systems, leadership, and tacit knowledge. Journal of management, 42(2), 524-554. https://doi.org/10.1177/0149206313478189

Daud, S., \& Abdul Hamid, H. (2006). Successful knowledge sharing in private higher institutions education: factors and barriers. Paper presented at the Knowledge Management International Conference and Exhibition, Kuala Lumpur, June 6-8.

Dee, J., \& Leisyte, L. (2017). Knowledge sharing and organisational change in higher education. The Learning Organization, 24(5), 355-365. https://doi.org/10.1108/TLO-04-2017-0034

Fullwood, R., \& Rowley, J. (2017). An investigation of factors affecting knowledge sharing amongst UK academics. Journal of Knowledge Management, 21(5), 1254-1271. https://doi.org/10.1108/JKM-07-2016-0274

Fullwood, R., Rowley, J., \& McLean, J. (2019). Exploring the factors that influence knowledge sharing between academics. Journal of Further and Higher Education, 43(8), 1051-1063. https://doi.org/10.1080/0309877X.2018.1448928

Jiang, Z., \& Hu, X. (2016). Knowledge sharing and life satisfaction: The roles of colleague relationships and gender. Social Indicators Research, 126(1), 379-394. https://doi.org/10.1007/s11205-015-0886-9

Lee, P., Gillespie, N., Mann, L., \& Wearing, A. (2010). Leadership and trust: Their effect on knowledge sharing and team performance. Management Learning, 41(4), 473-491. https://doi.org/10.1177/1350507610362036

Marouf, L. (2016). The role of knowledge sharing culture in business performance. VINE Journal of Information and Knowledge Management Systems, 46(2), 154-174. https://doi.org/10.1108/VJIKMS-10-2014-0061

Phung, V. D., Hawryszkiewycz, I., Chandran, D., \& Ha, B. M. (2019). Promoting knowledge sharing amongst academics: A case study from Vietnam. Journal of Information \& Knowledge Management, 18(3), 195. https://doi.org/10.1142/S0219649219500321

Ramjeawon, P. V., \& Rowley, J. (2017). Knowledge management in higher education institutions: enablers and barriers in Mauritius. The Learning Organization, 24(5), 366-377. https://doi.org/10.1108/TLO-03-2017-0030

Raza, I., \& Awang, Z. (2020). Knowledge-sharing practices in higher educational institutes of Islamabad, Pakistan: an empirical study based on the theory of planned behaviour. Journal of Applied Research in Higher Education, 7(1), Special Issue on New Trends in Business, Economics and Management. https://doi.org/10.1108/JARHE-03-2020-0068

Seonghee, K., \& Boryung, J. (2008). An analysis of faculty perceptions: Attitudes toward knowledge sharing and collaboration in an academic institution. Library \& Information Science Research, 30(4), 282-290. https://doi.org/10.1016/j.lisr.2008.04.003

Shahzadi, I., Hameed, R. M., \& Kashif, A. R. (2015). Individual motivational factors of optimistic knowledge sharing behaviour among University academia. The Business \& Management Review, 6(1), 134.

Sohail, S. M., \& Daud, S. (2009). Knowledge sharing in higher education institutions. VINE, 39(2), 125-142. 
https://doi.org/10.1108/03055720910988841

Tan, C. N. L. (2016). Enhancing knowledge sharing and research collaboration among academics: the role of knowledge management. Higher education, 71(4), 525-556. https://doi.org/10.1007/s10734-015-9922-6

Wang, W. T., \& Hou, Y. P. (2015). Motivations of employees' knowledge sharing behaviours: A self-determination perspective. Information and Organization, 25(1), 1-26. https://doi.org/10.1016/j.infoandorg.2014.11.001

Yang, C., Yu, M., Hu, F., Jiang, Y., \& Li, Y. (2017). Utilising cloud computing to address big geospatial data challenges. Computers, environment and urban systems, 61, 120-128.

https://doi.org/10.1016/j.compenvurbsys.2016.10.010

Yu, D., \& Zhou, R. (2015). Tacit Knowledge Sharing Modes of University Teachers from the Perspectives of Psychological Risk and Value. International Journal of Higher Education,4(2), 214-224. https://doi.org/10.5430/ijhe.v4n2p214

\section{Copyrights}

Copyright for this article is retained by the author(s), with first publication rights granted to the journal.

This is an open-access article distributed under the terms and conditions of the Creative Commons Attribution license (http://creativecommons.org/licenses/by/4.0/). 